\title{
Paradoxical Psoriasis during IL-17 blockage: two memorable patients
}

Alexandra Maria Giovanna Brunasso ${ }^{1 *}$, Cesare Massone ${ }^{1}$

Dermatology Unit, Galliera Hospital, Genoa, Italy

*Corresponding Author: Alexandra Maria Giovanna Brunasso, Dermatology Unit Galliera Hospital Mura delle Cappuccine, 14 Genoa, Italy

Received date: July 19, 2021; Accepted date: July 23, 2021; Published date: July 29, 2021

Citation: A M G Brunasso, C Massone. (2021) Paradoxical Psoriasis during IL-17 blockage: two memorable patients. J. Dermatology and Dermatitis. 6(2); Doi: 10.31579/2578-8949/080

Copyright: (C2021 Alexandra Maria Giovanna Brunasso, This is an open-access article distributed under the terms of The Creative Commons. Attribution License, which permits unrestricted use, distribution, and reproduction in any medium, provided the original author and source are credited.

\begin{abstract}
:
47 year-old man who suffered for plaque psoriasis since 2013 was previously treated with topicals, UVB photherapy, acitretin, methotrexate and adalimumab (Imraldi ${ }^{\circledR}$ ) with scarce response. Brodalumab (IL-17 receptor chain A blocking antibody) at $210 \mathrm{mg}$ sc day 0, week-1, week-2 and every 2 weeks was initiated (baseline PASI of 16) with fast improvement of psoriasis (PASI-90 at week 4) and new onset of erythema, pustules and pain in the palmoplantar area after each subcutaneous Brodalumab administration and progressive improvement after 5-8 days.

Keywords: old man; uvb photherapy; corticosteroids; biopsy
\end{abstract}

\section{Case 1}

47 year-old man who suffered for plaque psoriasis since 2013 was previously treated with topicals, UVB photherapy, acitretin, methotrexate and adalimumab (Imraldi ${ }^{\circledR}$ ) with scarce response. Brodalumab (IL-17 receptor chain A blocking antibody) at $210 \mathrm{mg}$ sc day 0 , week-1, week-2 and every 2 weeks was initiated (baseline PASI of 16) with fast improvement of psoriasis (PASI-90 at week 4) and new onset of erythema, pustules and pain in the palmoplantar area after each subcutaneous Brodalumab administration and progressive improvement after 5-8 days (Fig. 1a, 1b). Diagnosis of palmoplantar pustulosis (PPP) was made, blood laboratory diagnostics were in the normal range. The patient denied consensus for a skin biopsy. Due to the discomfort associated to the onset of PPP after each Brodalumab injection a switch to Guselkumab (IL-23 neutralizing antibody, $100 \mathrm{mg}$ sc at week 0, week4 and every 8 weeks) was decided, with complete improvement of both PPP and plaque psoriasis after 14 weeks.

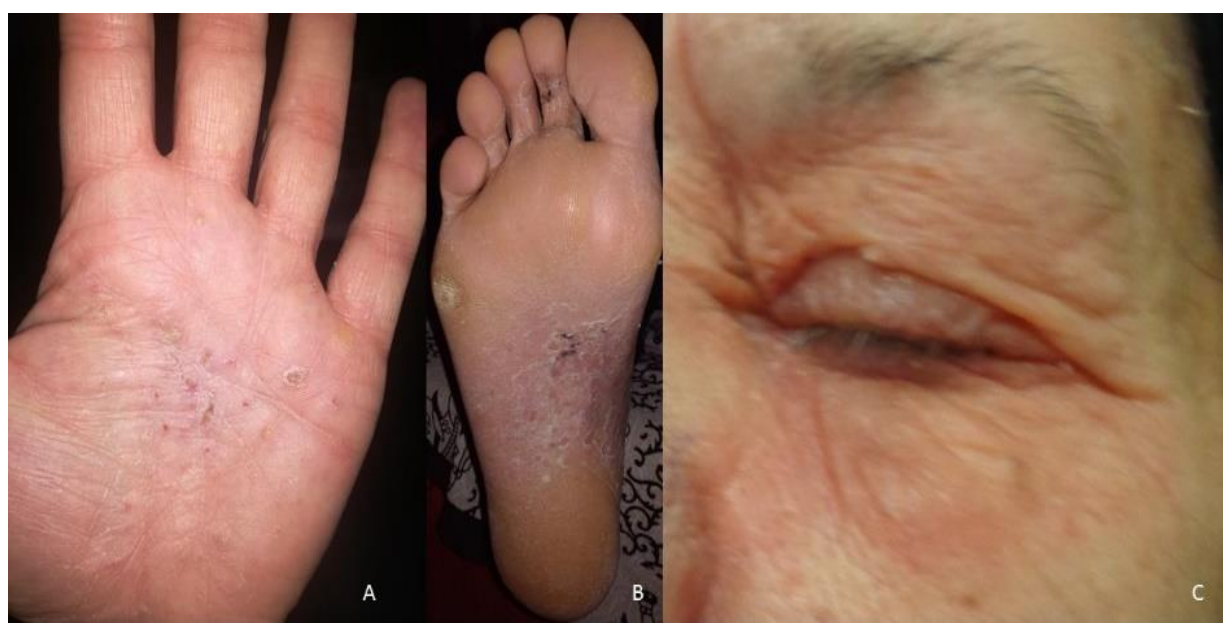


Figure 1A: pustules and scaling with crusts on the left palmar region.

Figure 1B: keratotic plaque with crusting, erythema and some pustules on the right plantar region

Figure 1C: well defined erythematous, scaling plaque on periocular area

\section{Case 2}

79-year-old female affected by plaque psoriasis since 1970, previously treated with topicals, UVB phototherapy, methotrexate with scarce response-initiated adalimumab (Humira $\left.{ }^{\circledR}\right) 4$ years before and withdrew therapy after 2 months because of the new-onset of Dermatomyositis (DM), prednisone $0.5 \mathrm{mg} / \mathrm{kg}$ per o.s was given for 2 years and during tapering psoriasis returned. The patient was reluctant to biological therapy and only after 2 years she accepted to initiate Secukinumab $300 \mathrm{mg} s \mathrm{sc}$ weeks, 0, 1, 2, 3,4 and every month thereafter for a diffuse plaque psoriasis (PASI: 19.2). Complete response with PASI-100 was observed at week-12, but she developed eye-lid lesions never seen before, denying pruritus, use of eye-drops or cosmetics and no other therapies were conducted. (Fig 1c) A skin biopsy was not performed because of dissent of the patient. Topical corticosteroids and thereafter pimecrolimus cream were required to control the eye-lid psoriasiform-eczema.

A paradoxical adverse event (PAE) is defined as the unexpected new onset or worsening of a condition during biologic therapy, when that particular condition otherwise responds well to the biologic agent involved [1]. New development of plaque or pustular psoriasis and psoriasis onset in anatomical sites never compromised before are the most common reported PAE [1,2]. Herein, we report two different psoriasisPAE during anti-IL-17 therapy: PPP and eye-lid psoriasiform-eczema; interestingly in the second case a prior PAE was reported during adalimumab (DM) $[3,4]$. TNF- $\alpha$ blocking agents may aggravate/trigger the onset of DM as demonstrated in a systematic literature review, in contrast to the proposed action as potential steroid-sparing agents in DM and polymyositis $[3,4]$. Psoriasis-PAE appears in $2-5 \%$ of anti-TNF- $\alpha$ treated patients and is driven by an ongoing type-I IFN innate immune response in the absence of $\mathrm{T}$ cell driven inflammation in contrast to chronic plaque psoriasis [1,2-5]. It has been postulated that psoriasis-PAE are seen exclusively during TNF- $\alpha$ blockade, but few cases have been reported during anti- IL-17 therapies, even if the underlying mechanism still needs to be elucidated [6-8]. The low-frequency of presentation (less than $5 \%$ ) indicates that other factors such as genetic predisposition or trigger factors influence the abrupt onset [1,5]. Noteworthy, epidermal trauma (Koebner phenomenon) which induces antimicrobial peptides (AMP)-expression by keratinocytes and attracts plasmacytoid dendritic cells (pDCs) into the skin, enhances the production of type-I IFN and the new onset of psoriasis [4]. We hypothesize that chronic trauma (Koebner phenomenon) in the palms and soles might trigger such condition as in our first patient [4]. The new onset of eye-lid psoriasiform-eczema in our second case, affecting an area usually spared by plaque psoriasis (involved only erythrodermic-psoriasis) has been previously reported in other three patients [8]. In both cases the rapid-onset of psoriasis-PAE suggests also a genetic predisposition (mean 2.5 weeks). We highlight that in our first case, anti-IL-23 therapy resulted in complete resolution of both the classical and paradoxical psoriasis.

Conflicts of interests: The authors have no conflict of interest.

The content of this paper has not been previously presented

We did not receive funding sources for this project

\section{References}

1. Puig L. (2018) Paradoxical Reactions: Anti-Tumor Necrosis Factor Alpha Agents, Ustekinumab, Secukinumab, Ixekizumab, and Others. Curr Probl Dermatol; 53:49-63.

2. Brunasso AM, Laimer M, Massone C. (2010) Paradoxical reactions to targeted biological treatments: A way to treat and trigger? Acta Derm Venereol;90:183-5.

3. Giovanna Brunasso AM, Fancelli L, Massone C. (2011) Etanercept as steroid-sparing agent in dermatomyositis. Ann Neurol; 70:670-1.

4. Brunasso AM, Aberer W, Massone C. (2014) New onset of dermatomyositis/polymyositis during anti-TNF- $\alpha$ therapies: a systematic literature review. ScientificWorldJournal; 2014:179180.

5. Conrad C, Di Domizio J, Mylonas A, Belkhodja C, Demaria O, Navarini AA, Lapointe AK, French LE, Vernez M, Gilliet M. (2018) TNF blockade induces a dysregulated type I interferon response without autoimmunity in paradoxical psoriasis. Nat Commun;9:25.

6. Mössner R, Pinter A. (2020) Paradoxical palmoplantar pustulosis induced by secukinumab and brodalumab: a report of three cases. Eur J Dermatol.

7. Abbruzzese A, Venerito V, Lopalco G, Fornaro M, Giannotta M, Iannone F. (2020) Paradoxical Pustular Psoriasis in a Patient With Psoriatic Arthritis on Secukinumab Treatment. J Clin Rheumatol; 26:e208-e209.

8. Pirro F, Caldarola G, De Simone C, Moretta G, Giovanardi G, Peris K. (2019) Multiple paradoxical reactions during ixekizumab therapy. Dermatol Ther;32:e12852.
This work is licensed under Creative Commons Attribution 4.0 License
Ready to submit your research? Choose Auctores and benefit from:

*ast, convenient online submission
*igorous peer review by experienced research in your field
rapid publication on acceptance
* authors retain copyrights
* imique DOI for all articles
immediate, unrestricted online access

At Auctores, research is always in progress.

Learn more https://auctoresonline.org/journals/dermatology-anddermatitis 